\title{
Transfer hydrogenation of benzaldehyde over embedded copper nanoparticles
}

\section{Co Thanh Thien ${ }^{1,2, *}$

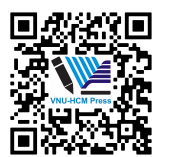 \\ Use your smartphone to scan this QR code and download this article}

\begin{abstract}
Introduction: Transfer hydrogenation is one of the reaction of high industrial applications, and copper catalyst is widely used in various hydrogenated substrates. Unfortunately, these hydrogenated processes were usually performed at high temperature, pressure, and a high concentration of catalyst. In this study, we have tried to reduce the dangerous condition by using copper nanoparticles as a catalyst, and the catalytic activity will be evaluated via the transfer hydrogenation of benzaldehyde. These results will be presented in this report. Methods: All the prepared catalysts were characterized by Scanning Electron Microscope (SEM), Transmission Electron Microscopy (TEM), X-ray diffraction (XRD), atomic absorption spectrometric (AAS), and Nitrogen adsorptiondesorption isotherms (BET). Results: Copper nanoparticles were synthesized via the reduction of copper salt and sodium borohydride. The particle size of copper was determined at 14-16 nm, and copper nanoparticles were well dispersed on the supports. Besides, copper nanoparticles have proved the active catalyst for transfer hydrogenation of benzaldehyde at low atmospheric pressure and temperature. Indeed, $97.8 \%$ conversion of benzaldehyde was observed within 60 min in activated carbon-supported copper nanoparticles as a catalyst. Conclusion: The lower concentration of copper particles in supports, the lower catalytic activity of transfer hydrogenation of benzaldehyde was observed. Namely, the conversion of benzaldehyde decreased to $72.7 \%$ in the case of $\mathrm{Cu}-\mathrm{Al}_{2} \mathrm{O}_{3}$, which was anchored $2.80 \%$ of copper according to AAS.

Key words: copper nanoparticles, nanocatalyst, hydrogenation, carbonyl groups
\end{abstract}

\section{${ }^{1}$ University of Science, Ho Chi Minh City, Vietnam \\ ${ }^{2}$ Vietnam National University, Ho Chi Minh City, Vietnam}

\section{Correspondence}

Co Thanh Thien, University of Science, Ho Chi Minh City, Vietnam

Vietnam National University, Ho Ch Minh City, Vietnam

Email: ctthien@hcmus.edu.vn

\section{History}

- Received: 2020-12-23

- Accepted: 2021-02-17

- Published: 2021-02-28

DOI : 10.32508/stdj.v24i1.2507

\section{Check for updates}

\section{Copyright}

(c) VNU-HCM Press. This is an openaccess article distributed under the terms of the Creative Commons Attribution 4.0 International license.

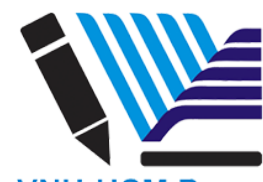

VNU-HCM Press

\section{INTRODUCTION}

Transfer hydrogenation has been studied since $1897^{1,2}$; it is still attracting the attention of many researchers by its convenient and powerful method to access a variety of industrial applications from organic synthesis to fine chemicals ${ }^{3,4}$. Recently, many researches have been reported with high efficiency, excellent chemoselectivity, long-lived stability, and easy recovery when palladium ${ }^{5-8}$ and nickel $^{9-11}$ catalyst were used.

However, not many publications have been found in copper nanoparticles' uses; most of the reports focused on the hydrogenation of alkyl ketones ${ }^{12,13}$, nitroarenes ${ }^{14}$, a polycyclic aromatic hydrocarbon ${ }^{15,16}$, quinolines, alkynes, imines ${ }^{17}$ etc... Unfortunately, the reduced condition was usually carried out at a high temperature and dangerous atmosphere pressure. For example, W. Li and coworkers hydrogenated quinolines in high yield, up to $98 \%$ over $\mathrm{Cu}-\mathrm{Al}_{2} \mathrm{O}_{3}$ catalyst at $120{ }^{\circ} \mathrm{C}$ under 50 bar of hydrogen pressure within $24 \mathrm{~h}^{18}$. Likewise, J. Wu et al. performed the hydrogenation of furfural at $150{ }^{\circ} \mathrm{C}$ under $4 \mathrm{Mpa}$ hydrogen pressure within 3 h, over $90 \%$ conversion was observed with $\mathrm{CuNi}_{3}-\mathrm{MgAlO}$ as catalyst ${ }^{19}$. According to K. Suthagar, glycerol was hydrogenated over $15 \mathrm{wt} \%$ of $\mathrm{Cu}-\mathrm{SiO}_{2}$ as a catalyst to obtain 1,2propanediol in $95 \%$ conversion at $200^{\circ} \mathrm{C}$ under 60 bar hydrogen pressure ${ }^{20}$.

Therefore, in an attempt to explore more the scope of catalytic processes available from embedded copper nanoparticles and reduce the high temperature, pressure, and amount of catalysts, we have tried to test the activity of the copper catalyst in a variety of organic synthesis reactions $^{21}$. In which transfer hydrogenation is one of the reaction of high industrial application. Besides, immobilization of the metallic nanoparticles on solid materials has received a great interest because of their use in industrial applications, especially hydrogenation of carbonyl compounds. Though nanomaterials serve as an excellent heterogeneous catalyst, they often need additional support to acquire thermal stability. Therefore, varieties of materials like zeolites, aluminum oxides, aluminosilicates, silica gel, chitosan, activated carbon, zinc oxides, etc., have been used as supports nanocatalysts $^{22-24}$. Among these materials, activated carbon, bentonites, aluminum oxide, zeolites, and zinc oxide 
are widely used as catalysts and support for the number of reactions.

This study focused on copper nanoparticles' preparation embedded on the supports such as bentonites, zeolites, activated carbon, zinc oxide, and aluminum oxide. Catalytic activity was evaluated via the transfer hydrogenation of benzaldehyde. The results will be presented in this report.

\section{MATERIALS AND METHODS}

\section{Materials}

Unless otherwise noted, all experiments were carried out in the air. Reagent grade copper (II) sulfate pentahydrate $98 \%\left(\mathrm{CuSO}_{4} .5 \mathrm{H}_{2} \mathrm{O}\right)$, aluminum oxide $99 \%$ $\left(\mathrm{Al}_{2} \mathrm{O}_{3}\right)$, zinc oxide $99 \%(\mathrm{ZnO})$, benzaldehyde $99 \%$, and sodium borohydride $98 \%\left(\mathrm{NaBH}_{4}\right)$ were purchased from Merck (Germany). Potassium hydroxide 98\%, zeolite (Zeolit), and polyvinyl pyrrolidone K-30 (PVP) were purchased from various Chinese suppliers (Xilong, China). Binh Thuan bentonite (Bent) and activated carbon were purchased from the local suppliers (Binh Thuan, Vietnam). Absolute ethanol and isopropanol were supplied by Chemsol (Ho Chi Minh City, Vietnam) and used as received.

\section{Characterization}

The morphology of catalysts was examined by scanning electron microscope (SEM, Hitachi S4800, Japan). Transmission Electron Microscopy (TEM) images were collected using FEI Tecnai G2 F20 (University of Technology, Ho Chi Minh City). The X-ray diffraction (XRD) data of all samples was collected in a Bruker D8 powder X-Ray (Vietnam Petroleum Institute, Ho Chi Minh City) with $\mathrm{Cu} \mathrm{K} \alpha$ radiation running at $35 \mathrm{kV} / 30 \mathrm{~mA}$ in the $2 \theta$ range $5^{\circ}, 75^{\circ}$ with a step size of $0.2^{\circ} / \mathrm{min}$. Nitrogen adsorptiondesorption isotherms were collected at $77 \mathrm{~K}$ using Brunauer-Emmett-Teller calculation (AUTOSORB1C Quantachrome, INOMAR center, VNU-HCM), all the samples were degassed at $100{ }^{\circ} \mathrm{C}$ and $10^{-6}$ $\mathrm{Pa}$. Atomic absorption pectroscopy (AAS) was analyzed on Agilent 240AAS (Laboratory of AnalysisUniversity of Science, Ho Chi Minh City). GC-MS was obtained using an Agilent 7890A series model with an electron energy of 20 or $70 \mathrm{eV}$ (Laboratory of Natural compound, University of Science, Ho Chi Minh City). All the catalytic test were performed in Multireactors Carousel 12 plus (Laboratory of Catalysis- University of Science, Ho Chi Minh City).

\section{Catalyst preparation}

To the $250 \mathrm{~mL}$ two-necked round bottom flask, $0.4 \mathrm{~g}$ of PVP and $70 \mathrm{~mL}$ of deionized water (DI) were added. After stirring for $15 \mathrm{~min}, 0.50 \mathrm{~g}$ of $\mathrm{CuSO}_{4} .5 \mathrm{H}_{2} \mathrm{O}(2.0 \mathrm{mmol})$ was dissolved in the mixture at $80^{\circ} \mathrm{C}$. In another flask, $0.15 \mathrm{~g}$ of $\mathrm{NaBH}_{4}$ in 50 $\mathrm{mL}$ of DI water was prepared. Then, the solution of the reducing agent was dropwise added to the mixture of copper salt. The mixture was stirred for $6 \mathrm{~h}$ until the black solution appeared.

The copper nanoparticles were then loaded into the supports $\mathrm{X}\left(\mathrm{X}=\mathrm{Bent}, \mathrm{C}\right.$, Zeolit, $\mathrm{ZnO}$, and $\mathrm{Al}_{2} \mathrm{O}_{3}$, which were calcinated at $120^{\circ} \mathrm{C}$ in $8 \mathrm{~h}$ ) in a suitable amount by low-pressure method at room temperature. This process was repeated several times to make sure all the copper nanoparticles were fully loaded into the supports. The obtained powders were dried at $80^{\circ} \mathrm{C}$ under vacuum for $5 \mathrm{~h}$.

\section{Catalyst evaluation}

In this work, the catalytic activity of copper nanocatalysts was investigated via the hydrogenation of benzaldehyde under the liquid phase in the presence of potassium hydroxide. The catalytic evaluation of $\mathrm{Cu}$ $\mathrm{X}$ was carried out in $20 \mathrm{~mL}$ multi reactor with stirring at $60{ }^{\circ} \mathrm{C}$ under reflux condensation. In this process, $5.0 \mathrm{~mol} \%$ of $\mathrm{Cu}-\mathrm{X}$ was used to hydrogenate benzaldehyde (5.0 mmol), isopropanol (IPA, $5.0 \mathrm{~mL}$ ), and $1.0 \mathrm{~mL}$ of potassium hydroxide solution $5 \%$ in isopropanol. Hydrogen was directly connected through Schlenk line to the reaction at atmospheric pressure within $60 \mathrm{~min}$. The conversion of substrate and selectivity of products were analyzed by GC and GC-MS (HP5 column 30 m x 0.25 mm, FID detector). Reproducibility was checked by repeating the measurement several times and was found to be within acceptable limit.

\section{RESULTS}

Copper nanoparticles were simply synthesized by the reduction of copper sulfate pentahydrate using sodium borohydride as reduction agents. The mixture of nanoparticles was then loaded into supports X with various concentrations, as seen in Table 1. AAS analysis indicated that the content of copper in $\mathrm{C}$ was highest at $8.61 \%$, and similarly 7.39, 7.36, 6.28, and $2.80 \%$ in $\mathrm{Zeolit}, \mathrm{ZnO}$, Bent, and $\mathrm{Al}_{2} \mathrm{O}_{3}$ were obtained, respectively.

Besides, as shown in Figure 1 two reflection peaks centered at $2 \theta$ of $43.4^{\circ}$ and $50.2^{\circ}$ are assigned for $\mathrm{Cu}^{0}$, indexed to the (111) and (200) plane of copper (JCPDS 004-0836). This confirmed the reduction of 


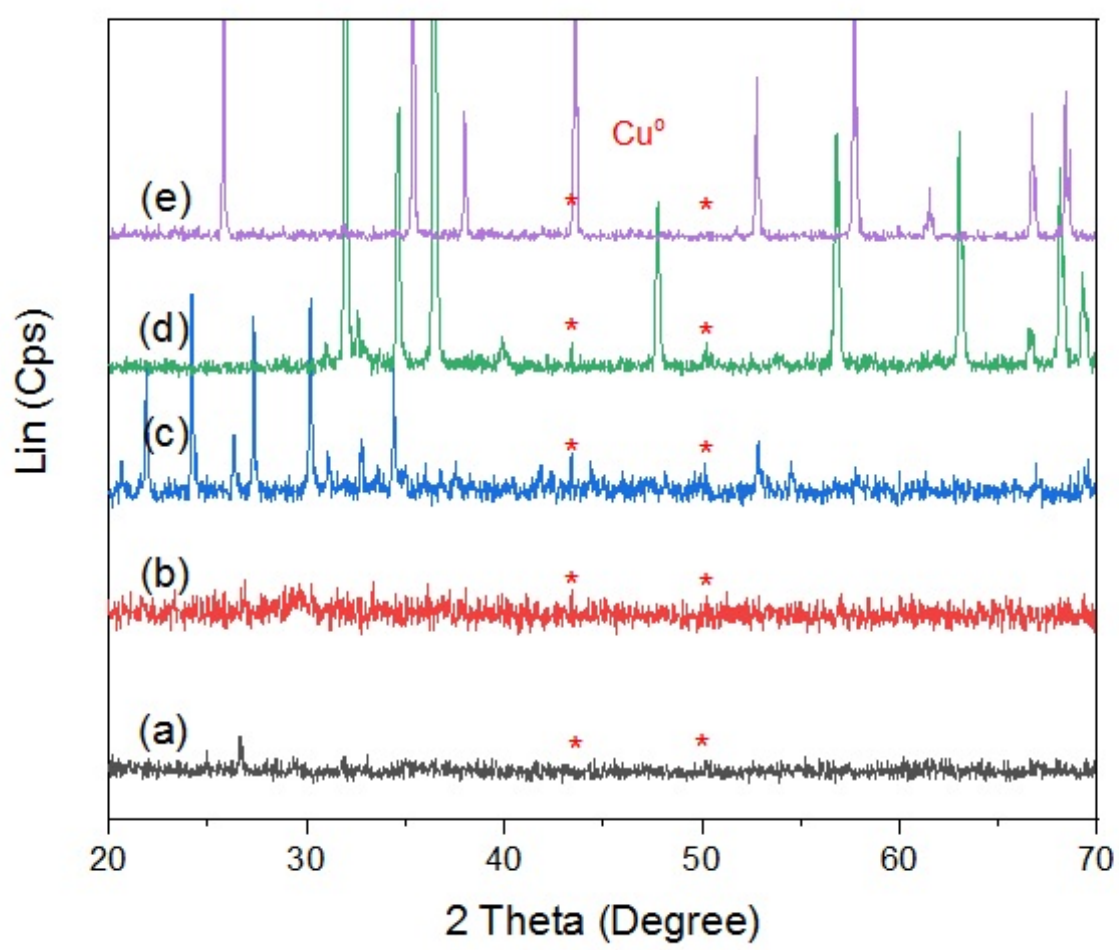

Figure 1: XRD patterns of a) $\mathrm{Cu}$-Bent; b) $\mathrm{Cu}-\mathrm{C}$; c) $\mathrm{Cu}$-Zeolit; d) $\mathrm{Cu}-\mathrm{ZnO}$; and e) $\mathrm{Cu}-\mathrm{Al}_{2} \mathrm{O}_{3}$. All were dried at 60 ${ }^{\circ} \mathrm{C}$ under vacuum for $8 \mathrm{~h}$ without further calcination.

copper salt to metallic copper ${ }^{20}$. Even though the peaks are quite weak because of the low concentration of metal particles in the samples. Furthermore, the corresponding diffraction peaks of $\mathrm{ZnO}$, Zeolit and $\mathrm{Al}_{2} \mathrm{O}_{3}$ located at the position of $2 \theta=29.95^{\circ} ; 34.62^{\circ}$; $36.49^{\circ}$; $47.75^{\circ}$; $56.72^{\circ} ; 63.01^{\circ}, 21.90^{\circ} ; 24.21^{\circ}$; $27.43^{\circ}$; $30.25^{\circ} ; 33.21^{\circ} ; 34.53^{\circ} ; 36.17^{\circ} ; 45.50^{\circ}$; and $25.90^{\circ}$; $35.43^{\circ} ; 38.04^{\circ} ; 43.61^{\circ} ; 52.92^{\circ} ; 57.77^{\circ} ; 66.80^{\circ} ; 68.42^{\circ}$, re pectively. Meanwhile, $\mathrm{C}$ and Bent are amorphous lattice structures leading to the XRD patterns as the noise at the baseline (Figure 1a and Figure 1b).

On the other hand, TEM images of copper nanoparticles in Figure 2a showed that these nanoparticles had a spherical morphology with an average particle size in the range of $14,16 \mathrm{~nm}$. Moreover, Zeolit supported $\mathrm{Cu}$ nanoparticles in Figure $2 \mathrm{~b}$ described that almost all the copper nanoparticles were well dispersed on Zeolit. Whereas SEM defined the morphology surface of catalysts; in fact, in Figure 3a, the surface of $\mathrm{Cu}$ Bent was occupied by slit-shaped pores. Meanwhile, in Figure 3b-e the spherical shapes of $\mathrm{Cu}$ were attached on the surface and inside the supports' pores.

\section{DISCUSSION}

Copper nanoparticles were usually synthesized by the reduction of copper salt using different methods. In reality, J. Wu and coworkers performed via the hydrothermal reduction at high temperature in order to reduce copper nitrate to metallic copper under hydrogen flow ${ }^{12}$. Likewise, L. Lin et al. carried out reducing copper nitrate at $500{ }^{\circ} \mathrm{C}$ by tetramethylammonium hydroxide as a reducing agent ${ }^{25}$. R. Beerthuis and coworkers used the incipient wetness impregnation method to reduce copper precursors following to calcinate at high temperature ${ }^{13}$. In sum, all these methods required high temperature and long time calcinated, leading to low yield and danger for the handle. Therefore, in this study, we prepared the copper nanoparticles by reducing sodium borohydride at RT, following in situ loaded into supports X. The XRD patterns in Figure 1 indicated that all the copper ions were reduced to metallic copper. On the other hand, in the presence of PVP, copper nanoparticles were more stable, it could be explained in terms of the distribution of copper nanoparticles in the PVP solution, which is a well-known polymer with a large molecular size and free-electron couple on nitrogen site that 

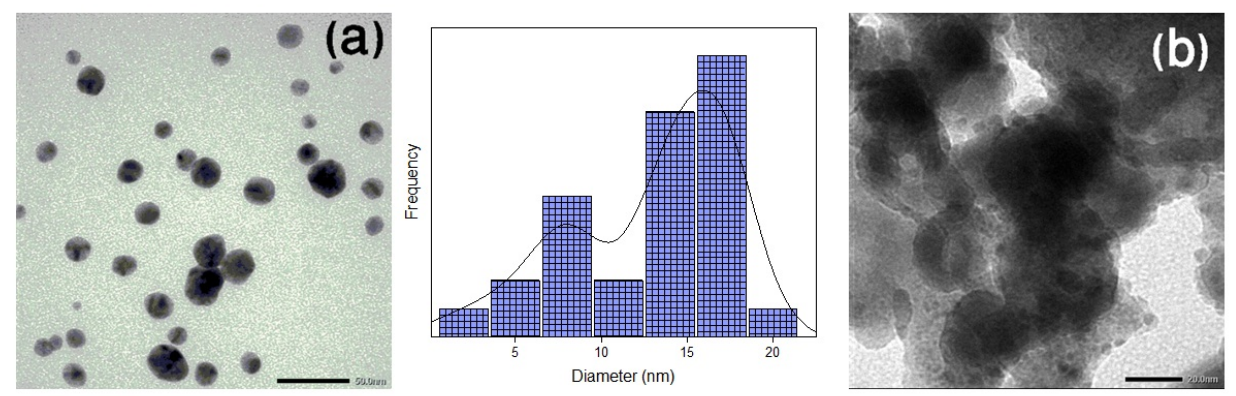

Figure 2: TEM images of a) Cu nanoparticles taken at $50 \mathrm{~nm}$; b) Cu-Zeolit taken at $20 \mathrm{~nm}$.

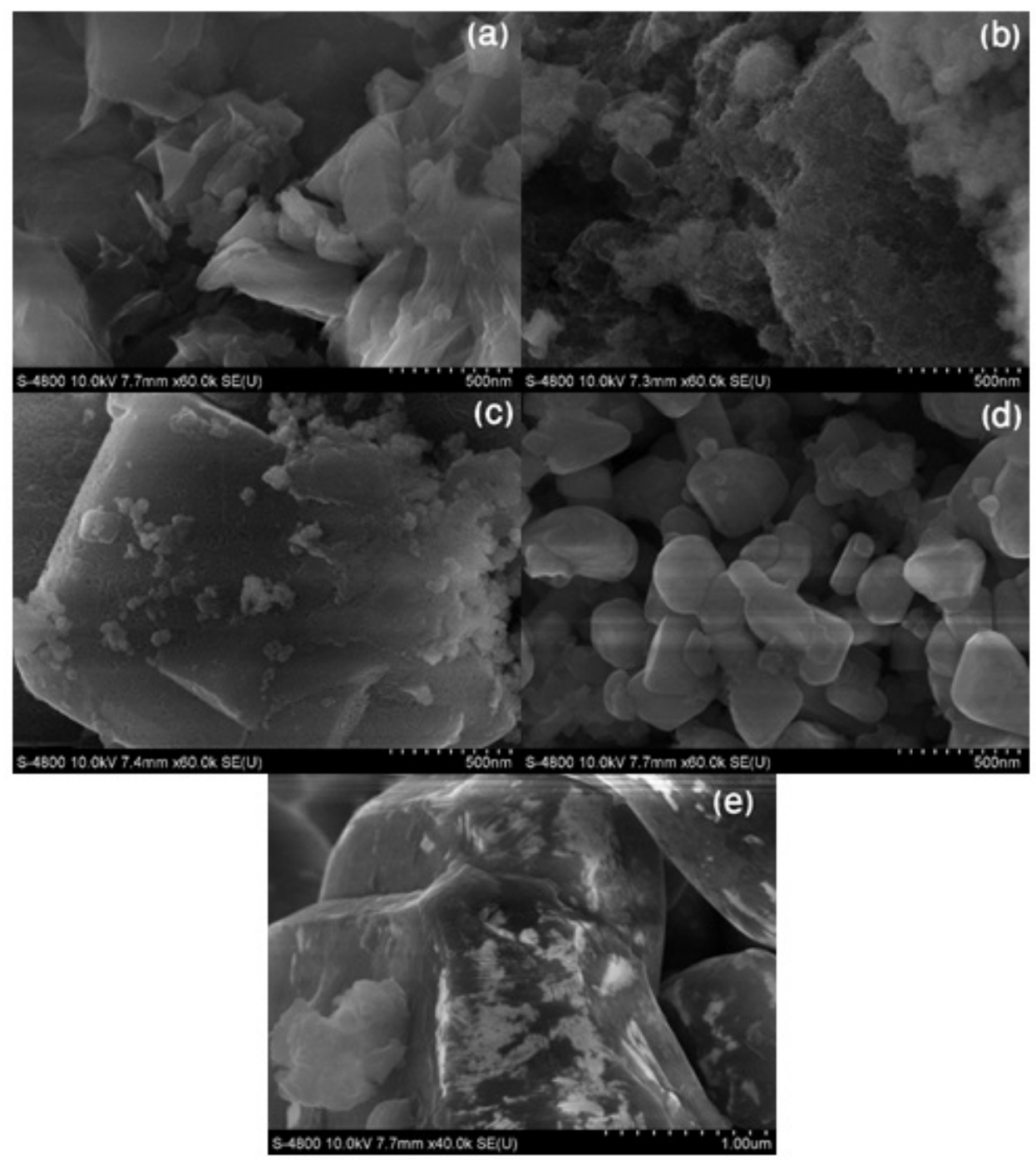

Figure 3: SEM images of a) $\mathrm{Cu}-\mathrm{Bent}$; b) $\mathrm{Cu}-\mathrm{C}$; c) $\mathrm{Cu}$-Zeolit; d) $\mathrm{Cu}-\mathrm{ZnO}$; e) $\mathrm{Cu}-\mathrm{Al}_{2} \mathrm{O}_{3}$. The images were taken at $500 \mathrm{~nm}$ and $1.0 \mu \mathrm{m}$. 
can bond with copper nanoparticles. Hence PVP acts as a protecting agent to avoid the agglutination and deposition of copper nanoparticles.

Besides, Table 1 illustrated that $\mathrm{Cu}-\mathrm{Zeolit}$ and $\mathrm{Cu}$ $\mathrm{Al}_{2} \mathrm{O}_{3}$ possessed a low specific surface area of 31.36, and $6.40 \mathrm{~m}^{2} \mathrm{~g}^{-1}$, respectively. Meanwhile, Cu-Bent and $\mathrm{Cu}-\mathrm{C}$ has a high specific surface area of 49.50 , and $107.70 \mathrm{~m}^{2} \mathrm{~g}^{-1}$, respectively. Interestingly, in the case of $\mathrm{Cu}-\mathrm{ZnO}$ the surface area slightly increases after loaded copper nanoparticles, namely $55.30 \mathrm{~m}^{2} \mathrm{~g}^{-1}$ was obtained compared to the parent support $\mathrm{ZnO}$ of $48.75 \mathrm{~m}^{2} \mathrm{~g}^{-1}$, it could be explained that most of copper nanoparticles were deposited into the pores and on the surface of $\mathrm{ZnO}$ which was evidenced on the SEM image as shown in the Figure 3d.

To evaluate the efficiency of the catalysts, the transfer hydrogenation of benzaldehyde was performed in the presence of potassium hydroxide in isopropanol within $60 \mathrm{~min}$. All the experiments were carried out at $60{ }^{\circ} \mathrm{C}$ and summarized in Figure 4. In which the conversion of benzaldehyde was up to $97.8 \%$ in the case of $\mathrm{Cu}-\mathrm{C}$ catalyst, it could be explained in terms of the specific surface area as well as the AAS analysis of $\mathrm{Cu}-\mathrm{C}$, namely surface area of $\mathrm{Cu}-\mathrm{C}$ was over $107 \mathrm{~m}^{2} \mathrm{~g}^{-1}$ and the highest concentration of $\mathrm{Cu}$ on supported $\mathrm{C}$ was $8.61 \%$. Likewise, the $\mathrm{Cu}-\mathrm{ZnO}$ catalyst gave the high activity in the transfer hydrogenation of benzaldehyde as well, $93.3 \%$ conversion was obtained within $60 \mathrm{~min}$. However, in the case of $\mathrm{Cu}$ $\mathrm{Al}_{2} \mathrm{O}_{3}$, the conversion of benzaldehyde slightly decreased to $72.7 \%$ because of the low concentration of copper particles in $\mathrm{Al}_{2} \mathrm{O}_{3}$ at $2.8 \%$, as seen in Figure 5. Even though the parent supports alone possessed the moderate conversion. These were confirmed that copper catalysts were active in the transfer hydrogenation of carbonyl substrates under mild conditions even though the low concentration of copper in the catalyst.

\section{CONCLUSION}

This study demonstrated that copper nanoparticles are the powerful catalysts for the transfer hydrogenation of carbonyl substrates at low temperatures. Namely, the conversion was up to $97.8 \%$ within 60 min in the hydrogenation of benzaldehyde in activated carbon-supported copper nanoparticles. Besides, all the copper catalysts were characterized in detail, in which the size of copper nanoparticles is around 14-16 nm, and all copper ions were reduced to metallic ones.

\section{ABBREVIATIONS}

Bent: bentonites

DI: deionized

FID: flame ionization detector

PVP: polyvinyl pyrrolidone-K30

Zeolit: zeolites

\section{COMPETING INTERESTS}

The author (s) declare that there are no conflicts of interest regarding the publication of this paper.

\section{ACKNOWLEDGMENT}

This research is funded by the Graduate University of Science and Technology under grant number GUST.STS.ĐT2020- HH09. The author especially thanks to University of Science - Ho Chi Minh City for technical support.

\section{REFERENCES}

1. Knoevenagel E, Bergdolt B. Ueber das Verhalten des $\Delta 2.5$ Dihydroterephtalsäure dimethylesters bei höheren Temperaturen und in Gegenwart von Palladiummohr. Chem Ber [Internet]. 1903;36:2857-2860. Available from: https://doi.org/ 10.1002/cber.19030360334.

2. Wang D, Astruc D. The Golden Age of Transfer Hydrogenation [Internet]. Chemical Reviews. American Chemical Society. 2015;115:6621-6686. Available from: http://doi.org/10.1021/ acs.chemrev.5b00203.

3. AlAsseel AKA, Allgeier AM, Hargreaves JSJ, Kelly GJ, Kirkwood K, Lok CM. Swetlana Schauermann SRS, Sengupta SK. Hydrogenation Catalysts and Processes [Internet]. Jackson SD, editor. 2018;Available from: https://doi.org/10.1515/ 9783110545210.

4. Andrew R, Takahiro M, Seiji O. The development of aqueous transfer hydrogenation catalysts [Internet]. Vol. 40, Dalton Transactions. 2011;p. 10304-10310. Available from: http: //doi.org/10.1039/c1dt10544b.

5. Albin P, Jurka B, Igor M. Palladium-copper and palladium-tin catalysts in the liquid phase nitrate hydrogenation in a batchrecycle reactor. Appl Catal B Environ [Internet]. 2004;52(1):4960. Available from: https://doi.org/10.1016/j.apcatb.2004.02. 019\%0A.

6. Feng $Y, X u$ W, Huang $B$, Shao $Q, X u ~ L$, Yang $S$, et al. OnDemand, Ultraselective Hydrogenation System Enabled by Precisely Modulated Pd-Cd Nanocubes. J Am Chem Soc [Internet]. 2020;142(2):962-972. Available from: http://10.0.3.253/ jacs.9b10816.

7. Balouch A, Ali Umar A, Shah AA, Mat Salleh M, Oyama M. Efficient heterogeneous catalytic hydrogenation of acetone to isopropanol on semihollow and porous palladium nanocatalyst. ACS Appl Mater Interfaces [Internet]. 2013;5(19):98439849. Available from: http://doi.org/10.1021/am403087m.

8. Co TT. A highly efficient hydrogenation of carbonyl compounds over nano palladium catalyst. Vietnam J Catal Adsorpt [Internet]. 2015;4(3):60-64. Available from: http://chemeng. hust.edu.vn/jca/volumes-issues.

9. Sebakhy KO, Vitale G, Pereira-Almao P. Dispersed Ni-Doped Aegirine Nanocatalysts for the Selective Hydrogenation of Olefinic Molecules. ACS Appl Nano Mater [Internet]. 2018;1(11):6269-6280. Available from: https://doi.org/10. 1021/acsanm. 8 b01472.

10. Alonso F, Riente P, Sirvent JA, Yus M. Nickel nanoparticles in hydrogen-transfer reductions: Characterisation and nature of the catalyst. Appl Catal A Gen [Internet]. 2010;378(1):42-51. Available from: http://dx.doi.org/10.1016/j.apcata.2010.01.044. 
Table 1: Specific surface area and AAS analysis of catalysts

\begin{tabular}{ccccccc}
\hline Entry & Catalysts & & \multicolumn{3}{c}{$\mathbf{S}_{B E T}\left(\mathbf{m}^{2} \cdot \mathbf{g}^{-1}\right)$} & \\
& & Bent & $\mathbf{C}$ & Zeolit & $\mathbf{Z n O}$ & $\mathbf{A l}_{2} \mathbf{O}_{3}$ \\
1 & Blank & 54.08 & 318.36 & 64.78 & 48.75 & 16.99 \\
2 & $\mathrm{Cu}$ & 49.50 & 107.70 & 31.36 & 55.30 & 6.40 \\
AAS $(\% \mathrm{Cu})$ & & 6.28 & 8.61 & 7.39 & 7.36 & 2.80 \\
\hline
\end{tabular}

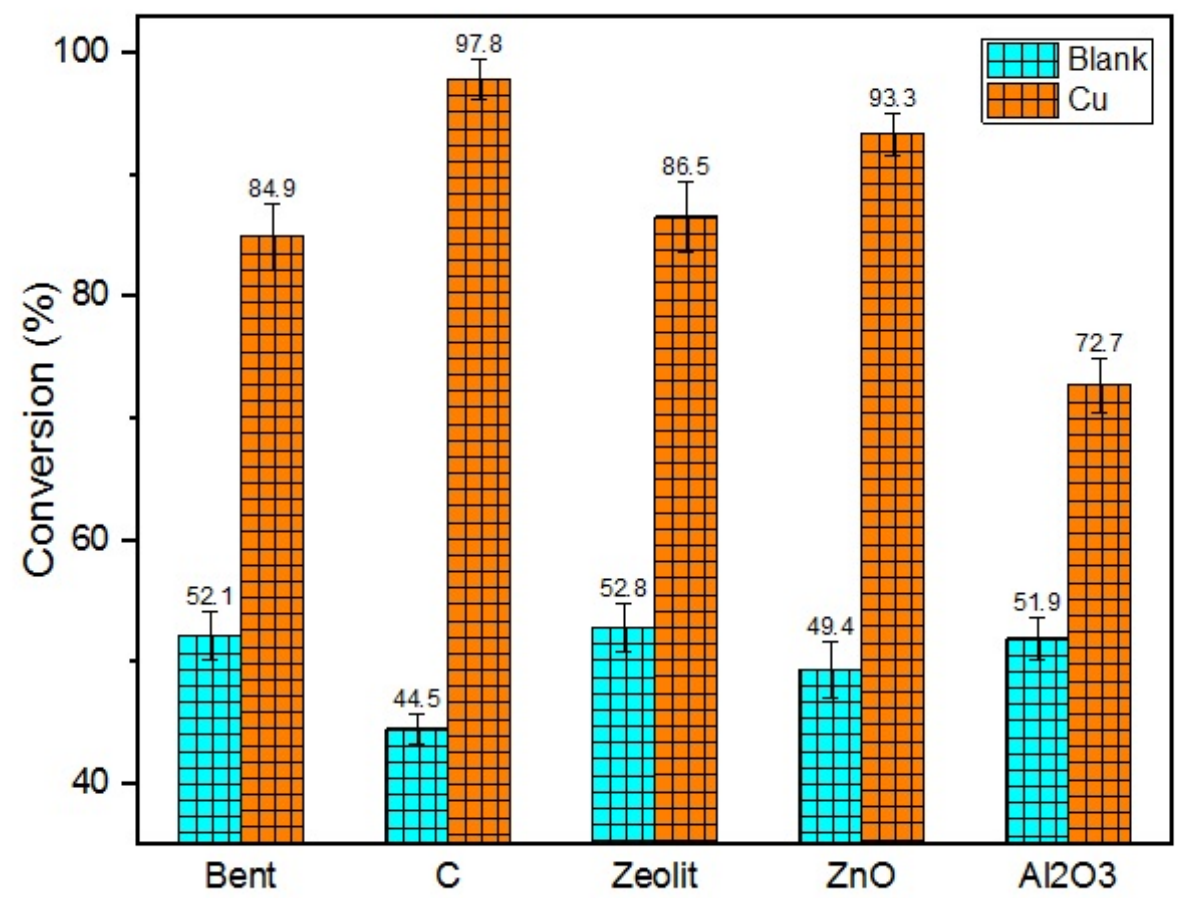

Figure 4: Conversion of transfer hydrogenation of benzaldehyde over $\mathrm{Cu}-\mathrm{X}$ catalysts $\mathrm{X}=\mathrm{Bent}$, $\mathrm{C}$, Zeolit, $\mathrm{ZnO}$, and $\mathrm{Al}_{2} \mathrm{O}_{3}$ ). Reaction condition: $5 \mathrm{~mol} \%$ of catalyst was used at $60^{\circ} \mathrm{C}$ within $1 \mathrm{~h}$.

11. Neelakandeswari N, Sangami G, Emayavaramban P, Ganesh Babu S, Karvembu R, Dharmaraj N. Preparation and characterization of nickel aluminosilicate nanocomposites for transfer hydrogenation of carbonyl compounds. J Mol Catal A Chem [Internet]. 2012;356:90-99. Available from: http://doi.org/10. 1016/j.molcata.2011.12.029.

12. Wu J, Gao G, Li J, Sun P, Long X, Li F. Efficient and versatile CuNi alloy nanocatalysts for the highly selective hydrogenation of furfural. Appl Catal B Environ [Internet]. 2017;203:227-236. Available from: http://dx.doi.org/10.1016/j.apcatb.2016.10.038.

13. Beerthuis R, de Rijk JW, Deeley JMS, Sunley GJ, de Jong KP, de Jongh PE. Particle size effects in copper-catalyzed hydrogenation of ethyl acetate. J Catal [Internet]. 2020;388:30-37. Available from: https://doi.org/10.1016/j.jcat.2020.05.006.

14. Liu X, Wang C, Cheng S, Shang N, Gao S, Feng C, et al. AgPd nanoparticles supported on reduced graphene oxide: $A$ high catalytic activity catalyst for the transfer hydrogenation of nitroarenes. Catal Commun [Internet]. 2018;108:103-107. Available from: http://dx.doi.org/10.1016/j.catcom.2018.02.001.

15. Lim KH, Mohammad AB, Yudanov I V., Neyman KM, Bron $M$ Claus $\mathrm{P}$, et al. Mechanism of selective hydrogenation of $r, \alpha$, $\beta$-unsaturated aldehydes on silver catalysts: A density func- tional study. J Phys Chem C [Internet]. 2009;113(30):1323113240. Available from: http://doi.org/10.1021/jp902078c.

16. Ungureanu A, Chirieac A, Ciotonea C, Mazilu I, Catrinescu C, Petit $S$, et al. Enhancement of the dispersion and catalytic performances of copper in the hydrogenation of cinnamaldehyde by incorporation of aluminium into mesoporous SBA-15 silica. Appl Catal A Gen [Internet]. 2020;598:117615-117624. Available from: https://doi.org/10.1016/j.apcata.2020.117615.

17. Wang $X$, Chen $M$, Chen $X$, Lin R, Zhu H, Huang $C$, et al. Constructing copper-zinc interface for selective hydrogenation of dimethyl oxalate. J Catal [Internet]. 2020;383:254-263. Available from: https://doi.org/10.1016/j.jcat.2020.01.018.

18. Li W, Cui X, Junge K, Surkus AE, Kreyenschulte C, Bartling S, et al. General and Chemoselective Copper Oxide Catalysts for Hydrogenation Reactions. ACS Catal. 2019;9(5):4302-4307. Available from: https://doi.org/10.1021/acscatal.8b04807.

19. Zhang $Y$, Zheng N, Wang $K$, Zhang S, Wu J. Effect of copper nanoparticles dispersion on catalytic performance of $\mathrm{Cu} / \mathrm{SiOcatalyst}$ for hydrogenation of dimethyl oxalate to ethylene glycol. J Nanomater [Internet]. 2013;2013:1-6. Available from: http://dx.doi.org/10.1155/2013/629375. 


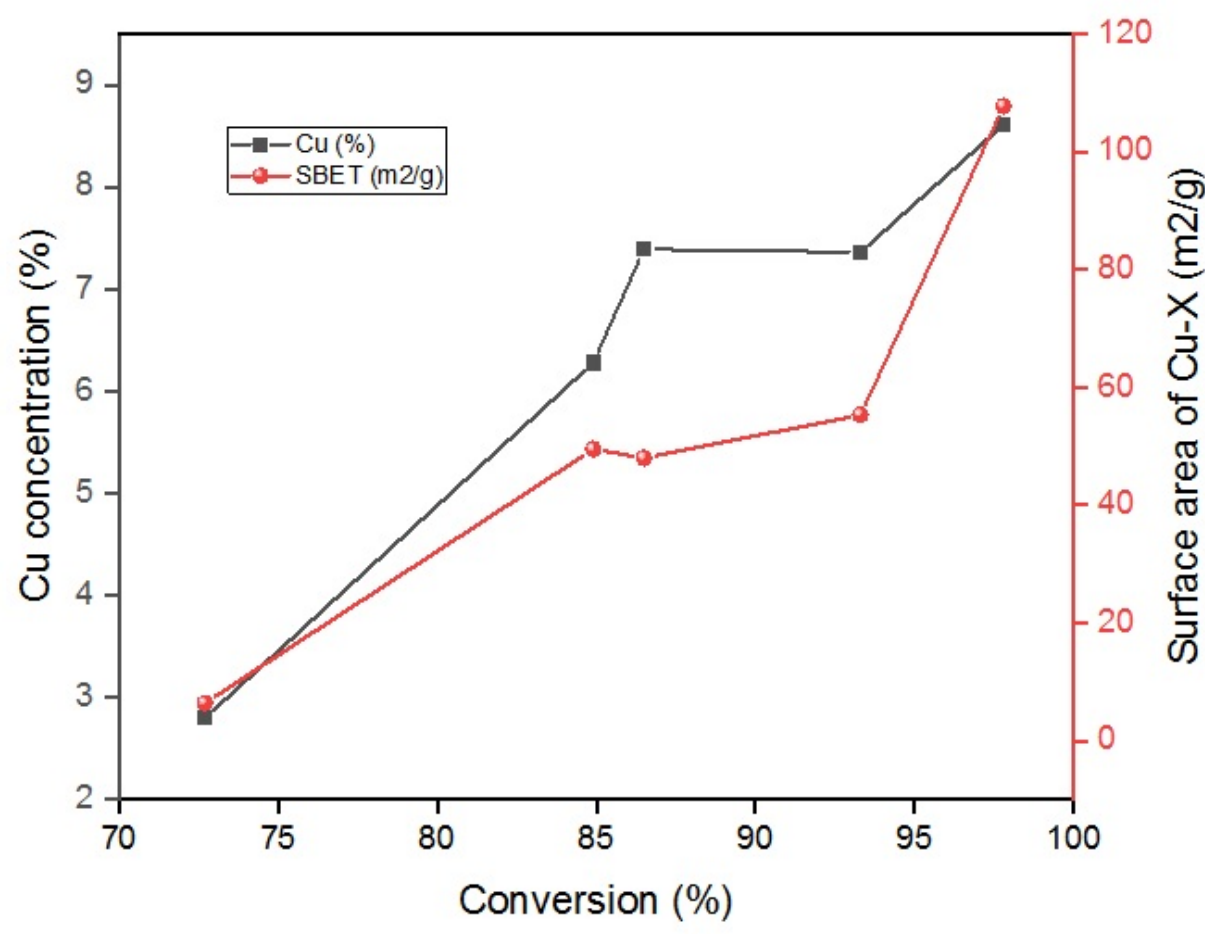

Figure 5: Influence of $\mathrm{Cu}$ concentration and surface area of catalysts on the conversion of benzaldehyde.

20. Suthagar K, Shanthi K, Selvam P. Hydrogenolysis of glycerol over silica-supported copper-nanocatalyst: Effect of precipitating-agent and copper metal-loading. Mol Catal [Internet]. 2018;458:307-316. Available from: https://doi.org/10. 1016/j.mcat.2017.11.035.

21. Iwao O. Catalytic Asymmetric Synthesis [Internet]. Wiley. Sons JW\&, editor. 2010;Available from: https://doi.org/10.1002/ 9780470584248

22. Khan I, Saeed K, Khan I. Nanoparticles: Properties, applications and toxicities [Internet]. Vol. 12, Arabian Journal of Chemistry. Elsevier B.V. 2019;p. 908-931. Available from: http://doi.org/ 10.1016/j.arabjc.2017.05.011.

23. Jiang P, Li X, Gao W, Wang X, Tang Y, Lan K, et al. Highly selective hydrogenation of $\mathrm{A}, B$-unsaturated carbonyl compounds over supported Co nanoparticles. Catal Commun [Internet]. 2018;111:6-9. Available from: http://doi.org/10.1016/j.catcom. 2018.03.017.

24. Lan NTK, Duoc NT, Duy NN, Van Chung C, Du BD, Hien NQ. Synthesis of Ag nano/TiO 2 by electron beam irradiation for photo-degradation of rhodamine $B$ compound in water. Vietnam J Chem [Internet]. 2020;58(3):398-403. Available from: http://doi.org/10.1002/vich.202000009.

25. Lin L, Yao S, Liu Z, Zhang F, Li N, Vovchok D, et al. In Situ Characterization of $\mathrm{Cu} / \mathrm{CeO} 2$ Nanocatalysts for $\mathrm{CO} 2 \mathrm{Hy}-$ drogenation: Morphological Effects of Nanostructured Ceria on the Catalytic Activity. J Phys Chem C [Internet]. 2018;122(24):12934-12943. Available from: http://doi.org/10. $1021 /$ acs.jpcc.8b03596. 